\title{
Revisión de bacterias lácticas en productos lácteos basado en el etiquetado.
}

Review of lactic bacteria in dairy products based on labeling.

Itzel G. Ángeles-Sanjuán ${ }^{a,}$ José E. Enríquez-Tadeo ${ }^{b}$, Lizbeth P. Hernández-

Carmona $^{c}$, Lourdes Hernández-Naranjo ${ }^{d}$, Eli Mireya Sandoval-Gallegos ${ }^{e}$,

\author{
Araceli Ortiz-Polo ${ }^{f}$ y Esther Ramírez-Moreno ${ }^{g}$
}

\begin{abstract}
:
According to the CODEX ALIMENTARIUS, fermented milks are dairy products obtained through the fermentation of milk, with or without changes in the composition, they are characterized by a specific crop (or specific crops) used for fermentation. The objective of this work was to review the presence of lactic acid bacteria in the labeling of Greek yogurt and fermented milk drinks. The labeling of both products complied with the amount of protein and fat according to the requirements established by NOM-086 -SSA1-1994. Although these products are vehicles of probiotic bacteria, they have high sugar content; therefore, their consumption should be moderate. Finally, the fermented dairy products evaluated were called fermented dairy products, they did not comply with the legislation specifying the type and quantity (CFU) of added lactic microorganisms. It is very important that brands account with this information, which will allow us to have a knowledge about which product could be recommended for the beneficial effect on the population's health.
\end{abstract}

Keywords: Yoghurt, lactic bacteria cultures, lactic acid

\section{Resumen:}

De acuerdo al CODEX ALIMENTARIO, las leches fermentadas son productos lácteos obtenidos por medio de la fermentación de la leche, con o sin modificaciones en la composición, se caracterizan por un cultivo específico (o cultivos específicos) utilizado para la fermentación. El objetivo de este trabajo fue realizar una revisión de la presencia de bacterias ácidos lácticas en el etiquetado de yogurt griego y bebidas lácteas fermentadas. El etiquetado de ambos productos cumplió con la cantidad de proteína y grasa de acuerdo a los requerimientos establecidos por la NOM-086SSA1-1994. A pesar de que estos productos son vehículos de bacterias probióticas, presentan un alto contenido de azucares, por lo tanto, su consumo debe de ser moderado. Finalmente, los productos lácteos fermentados evaluados se hacían llamar como productos lácteos fermentados no cumplieron con la legislación de especificar el tipo y la cantidad (UFC) de microorganismos lácticos adicionados. Es de suma importancia que las marcas hagan referencia a dicha información lo que permitirá poder seleccionar dichos productos por el efecto benéfico hacia la salud de la población.

Palabras Clave: Yogurt, cultivos de bacterias lácticas, ácido láctico.

\footnotetext{
a Universidad Autónoma del Estado de Hidalgo, Instituto de Ciencias de la Salud, http://orcid.org/0000-0001-6346-4492, Email: an347771@uaeh.edu.mx

${ }^{\mathrm{b}}$ Universidad Autónoma del Estado de Hidalgo, Instituto de Ciencias de la Salud, http://orcid.org/0000-0002-2077-5829,

Email: en357946@uaeh.edu.mx

c Universidad Autónoma del Estado de Hidalgo, Instituto de Ciencias de la Salud, http://orcid.org/0000-0001-6254-0107, Email: he346816@uaeh.edu.mx

${ }^{\mathrm{d}}$ Universidad Autónoma del Estado de Hidalgo, Instituto de Ciencias de la Salud, https://orcid.org/0000-0002-2046-2734, Email: he347203@uaeh.edu.mx

${ }^{\text {e } U n i v e r s i d a d ~ A u t o ́ n o m a ~ d e l ~ E s t a d o ~ d e ~ H i d a l g o, ~ I n s t i t u t o ~ d e ~ C i e n c i a s ~ d e ~ l a ~ S a l u d, ~ h t t p: / / o r c i d . o r g / 0000-0001-8029-7243, ~}$ Email: ile544@hotmail.com

${ }^{\mathrm{f}}$ Universidad Autónoma del Estado de Hidalgo, Instituto de Ciencias de la Salud, https://orcid.org/0000-0001-5561-2221,

Email: arapolo@hotmail.com

${ }^{g}$ Autor de correspondencia, Universidad Autónoma del Estado de Hidalgo, Instituto de Ciencias de la Salud,

https://orcid.org/0000-0002-9928-8600,Email: esther_ramirez@uaeh.edu.mx
} 


\section{Introducción}

De acuerdo con el CODEX STAN 243-2003 la leche fermentada es un producto lácteo obtenido por medio de la fermentación de la leche, que puede haber sido elaborado a partir de productos obtenidos de la leche con o sin modificaciones en la composición por medio de la acción de microorganismos adecuados y teniendo como resultado la reducción del $\mathrm{pH}$ con o sin coagulación. Estos cultivos de microorganismos deben ser viables, activos y abundantes en el producto hasta la fecha de duración mínima.

En México se elaboran industrialmente de productos lácteos fermentados con una creciente demanda, permitiendo ofrecer al consumidor una gran gama de productos como es el yogurt, yakult, jocoque, labne ó jocoque árabe entre otros. Los cuales se han establecido como un producto de alto valor nutritivo y constituyen los principales vehículos para el aporte de bacterias probióticas aportando propiedades funcionales al consumidor (Yakult, s/f; Orozco, y col. 2018).

Se definen como probióticos a los microorganismos vivos que, al ser administrado en cantidades adecuadas, confieren un beneficio a la salud en el huésped, en particular de los productos lácteos en los niños y otros grupos de alto riesgo de la población. Se ha informado de que estos probióticos pueden desempeñar un importante papel en las funciones inmunitaria, digestiva y respiratoria (Guías Mundiales de la Organización Mundial de Gastroenterología, 2017).

La ingesta de probióticos mediante productos fermentados, tiene beneficios en la salud de los consumidores, impactando en la modificación de algunas de las funciones metabólicas que esta ejerce, como mejorar la absorción de determinados nutrientes, ayuda al mantenimiento del microbiota intestinal y estimulan el sistema inmunológico, favoreciendo la resistencia contra agentes dañinos. (Garrote y Bonet, 2017).

Por otra parte, los productos lácteos fermentados, en su mayoría, contienen una cantidad inferior de lactosa debido a que las bacterias desencadenan un proceso microbiano por el cual la lactosa (el azúcar de la leche) se transforma en ácido láctico (Conicet. 2015).

De acuerdo con Orozco y col, (2018) refiere que el ácido láctico, formado de la fermentación, tiene como función inhibir el desarrollo de la flora patógena en el tracto gastrointestinal como Escherichia coli o Salmonella, además de promover la formación del microbiota intestinal beneficiosa para el organismo (100 billones de bacterias).

Por lo tanto, el objetivo de este trabajo fue realizar una revisión de la presencia de bacterias ácidos lácticas en el etiquetado de productos de yogurt griego y bebidas lácteas fermentadas.

\section{Material y Métodos}

Se analizaron las etiquetas de 6 marcas diferentes de yogurt griego (Vitalinea, Yoplait, Lala, Oikos, Chobani y Fage) en presentaciones de 125 y $150 \mathrm{~g}$ y 6 diferentes bebidas fermentadas (Yakult LT 40, Yakult, Bio4, Benegastro, Gastro Protect y Activia) en muestras de $80 \mathrm{~mL}, 120,90,110$ y 100 $g$ respectivamente. Las muestras se adquirieron en diferentes supermercados (Wal-Mart, Soriana, Bodega Aurrera).

\section{Resultados y discusión.}

EI CODEX STAN 243-2003 especifica que el contenido proteico mínimo para un yogurt debe de ser de $2.7 \%$ y menos de $15 \%$ de grasa láctea. El yogurt griego es un producto concentrado después de la fermentación con el objetivo de incrementar el contenido de proteína a un mínimo de 5.6\%. Las bebidas lácteas fermentadas son productos obtenidos a partir de leche descremada pasteurizada por lo que el contenido de proteína y grasa es bajo $(2.7 \%$ proteína y menor a $10 \%$ grasa láctea). En el estudio realizado, todos los productos evaluados presentaron un porcentaje aceptable de proteína, en el caso del yogurt griego (> 5.6\%) (Tabla 1) mientras que para las bebidas lácteas fermentadas cumplieron al menos con el parámetro de $2.7 \%$ especificado para el yogurth (Tabla 2). En cuanto al contenido lipídico todos los productos presentaron valores por debajo del $15 \%$ especificado para el yogurth.

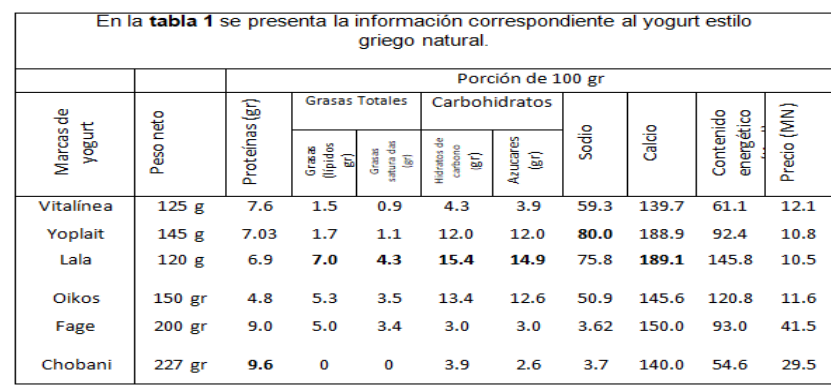

Con respecto a los hidratos de carbono no existe una legislación que establezca un porcentaje específico para las bebidas lácteas fermentadas. Considerando los carbohidratos presentes en la leche de vaca $(4 \mathrm{~g} / 100 \mathrm{~mL})$, el contenido de estos productos es alto, muy posiblemente por la adición de azúcares que se utilizan al enmascarar el pH ácido que caracteriza a estos productos. Tanto el yogur griego como las leches fermentadas presentaron valores de carbohidratos en un rango de 3.4 hasta $15.8 \mathrm{~g}$, lo cual redunda considerablemente con el aporte calórico de estos productos entre 37.5 a $145.8 \mathrm{kcal} / 100 \mathrm{~g}$ (Tabla 1 y 2).

Todos los productos evaluados presentaron un contenido menor a $140 \mathrm{mg} /$ porción sodio, por lo cual son considerados productos bajos en sodio de acuerdo a la NOM-086-SSA11994.

Finalmente, los productos lácteos fermentados son muy accesibles, ya que los podemos encontrar en casi todos los centros comerciales. Sin embargo, si consideramos que el precio del litro de leche es de 22 pesos, los productos evaluados son relativamente caros ya que fluctuaron entre los 7 y 12 pesos por unidad de 80 a $227 \mathrm{~g}$, siendo entonces solo accesibles a cierta clase de población que cuenta con las posibilidades para pagar el producto ó que conoce los beneficios de dichos productos. 


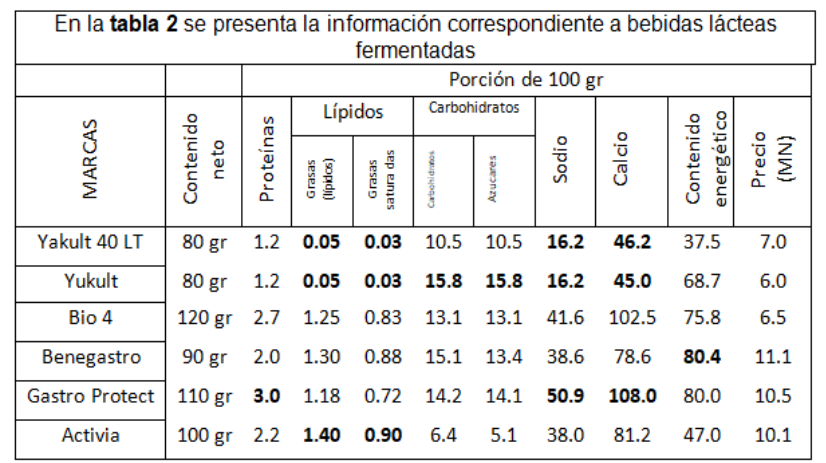

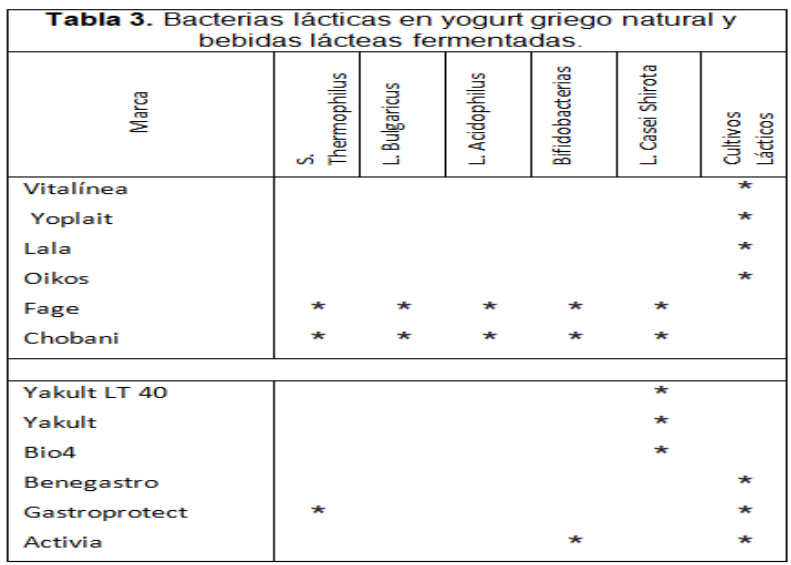

EI CODEX STAN 243-2003, establece que la suma de microorganismos que comprenden el cultivo en lo productos lácteos fermentados deberá ser de $10^{7} \mathrm{UFC} / \mathrm{g}$, y deberá estar referenciado en el etiquetado.

La mayoría de los productos fermentados referenciados en la tabla 3 no hacen mención en el etiquetado sobre el tipo de microorganismos que utiliza ni la cantidad denotando solamente la presencia de cultivos lácticos.

En el yogurt griego solamente las marcas extranjeras Chobani y Fage especifican 5 tipos de bacterias lácticas utilizadas. Con respecto a las bebidas lácteas fermentadas las etiquetas de los productos de la marca Yakult (Yakult LT40, Yakult y Bio4) mencionan que contienen Lactobacillus Casei Shirota y son los únicos que informan el número de UFC $\left(10^{7}\right)$. El producto Gastro Protect contiene bacterias lácticas como Streptococcus thermophilus y Lactobacillus Johnsonii además de cultivos lácticos y Activia informa un contenido de Bifidobacterias y también hace mención de cultivos lácticos, pero no especifica las UFC.

\section{Conclusiones}

- El etiquetado del yogurt griego y bebidas lácteas fermentadas cumplen con la cantidad de proteína y grasa de acuerdo a los requerimientos establecidos por la NOM-086-SSA1-1994.

- A pesar de que estos productos son vehículos de bacterias probióticas, presentan un alto contenido de azucares, por lo tanto, su consumo debe de ser moderado.

- Aunque los productos lácteos fermentados evaluados se hacen llamar como productos lácteos fermentados no cumplieron con la legislación de especificar el tipo y la cantidad (UFC) de microorganismos lácticos adicionados.

- Es de suma importancia que las marcas hagan referencia al contenido de bacterias lácticas (UFC) de microorganismos además del tipo, lo que permitirá tener un conocimiento sobre que producto pudiera ser recomendado por el efecto benéfico hacia la salud de la población.

\section{Referencias}

1. CODEX STAN 243-2003. Norma del codex para leches fermentadas. Leche y productos lácteos. 2da edición. P p. 1-8

2. Diario oficial de la federación. NOM-086-SSA1-1994, Bienes y servicios. Alimentos y bebidas no alcohólicas con modificaciones en su composición. Especificaciones nutrimentales. Recuperado de http://www.salud.gob.mx/unidades/cdi/nom/086ssa14.html Fecha de acceso: 21 de agosto del 2019.

3. Conicet. (2015). Bacteriófagos, los enemigos invisibles en la industria láctea. Recuperado de: http://www.dicyt.com/noticias/bacteriofagos-los-enemigosinvisibles-de-la-industria-lactea Fecha de acceso: 8 de septiembre del 2019.

4. Garrote, A; Bonet, R. (2017). Probióticos. ELSEVIER. Vol. 31 pp $13-16$.

5. Guías Mundiales de la Organización Mundial de Gastroenterología. (2017). Probióticos y prebióticos. p.p 4-5.

6. Orozco, C., Enríquez, A., Martínez, V., García, S., y Hernández, E. (2018). La ultrafiltración en la elaboración de yogurt estilo griego. Inv. y Desarrollo en Ciencia y Tecnología de Alimentos. Vol. 3. P.p. 344-351.

7. Yakult.s/f. Información para profesional de salud. Recuperado de:

http://www.yakult.mx/uploads_yakult/01_Guia_Medica_Yakul t.pdf Fecha de acceso: 08 de septiembre 2019 